\title{
Key regulators of sensitivity to immunomodulatory drugs in cancer treatment
}

\author{
Shichao Wang ${ }^{1 *}$, Zhiyue $\mathrm{Li}^{2}$ and Shaobing Gao ${ }^{2^{*}}$
}

\begin{abstract}
Immunomodulatory drugs (IMiDs) include thalidomide, lenalidomide, and pomalidomide, which have shown significant efficacy in the treatment of multiple myeloma (MM), myelodysplastic syndrome (MDS) with deletion of chromosome $5 q$ $($ del $(5 q))$ and other hematological malignancies. IMiDs hijack the CRL4 ${ }^{\text {CRBN }}$ ubiquitin ligase to target cellular proteins for ubiquitination and degradation, which is responsible for their clinical activity in MM and MDS with del(5q). However, intrinsic and acquired resistance frequently limit the efficacy of IMiDs. Recently, many efforts have been made to explore key regulators of IMiD sensitivity, resulting in great advances in the understanding of the regulatory networks related to this class of drugs. In this review, we describe the mechanism of IMiDs in cancer treatment and summarize the key regulators of IMiD sensitivity. Furthermore, we introduce genome-wide CRISPR-Cas9 screenings, through which the regulatory networks of IMiD sensitivity could be identified.
\end{abstract}

Keywords: Immunomodulatory drugs, CRISPR-Cas9 screening, CRL4 ${ }^{\text {CRBN }}$ E3 ligase, PROTACs, Multiple myeloma, Ubiquitination, CC-90009

\section{Background}

Thalidomide and its derivatives lenalidomide and pomalidomide are often called immunomodulatory drugs (IMiDs) due to their modulatory effects on immune cells [1-4]. IMiDs have shown remarkable therapeutic efficacy in several hematological malignancies. In combination with steroids, proteasome inhibitors and monoclonal antibodies, IMiDs are widely used to treat multiple myeloma (MM) [5-9]. Lenalidomide also has therapeutic activity in myelodysplastic syndrome (MDS) with deletion of chromosome $5 \mathrm{q}(\operatorname{del}(5 \mathrm{q}))[10,11]$, mantle cell lymphoma (MCL) [12-15] and chronic lymphocytic leukemia (CLL) [16-18]. New generations of IMiDs, including CC-122 (avadomide) [19-22], CC-

\footnotetext{
*Correspondence: shi_wang01@163.com; gaoshaobing@zju.edu.cn

${ }^{1}$ The Fifth Affiliated Hospital of Zhengzhou University, No. 3 Kangfu Front Street, 450052 Zhengzhou, China

${ }^{2}$ The Affiliated Cancer Hospital of Zhengzhou University, Henan Cancer Hospital, 127 Dongming Road, Zhengzhou 450008, China
}

220 (iberdomide) [23, 24], CC-885 [25, 26], CC-92480 [27] and CC-90009 [28] (Fig. 1), are being evaluated for their potential to treat diffuse large B-cell lymphoma (DLBCL), follicular lymphoma (FL), $M M$ and acute myeloid leukemia (AML) [29, 30].

Although IMiDs have shown significant efficacy in a range of hematological malignancies, primary and acquired drug resistance limit their clinical application. Thus, it is necessary to delineate the regulatory networks related to IMiD sensitivity. Recently, emerging evidence has shown that sensitivity to IMiDs is regulated by several factors, including CRBN, the Cullin-RING ligase 4 (CRL4) E3 ubiquitin ligase [31-34], RUNX proteins [35], and Wnt/ $\beta$-Catenin pathway members [36]. Moreover, genome-scale CRISPR screenings have identified a series of key regulators of sensitivity to IMiDs [37-41].

In this review, we highlight the underlying mechanisms of IMiDs in cancer treatment and summarize the key regulators of IMiD sensitivity. Furthermore, we

C C The Author(s). 2021 Open Access This article is licensed under a Creative Commons Attribution 4.0 International License, which permits use, sharing, adaptation, distribution and reproduction in any medium or format, as long as you give appropriate credit to the original author(s) and the source, provide a link to the Creative Commons licence, and indicate if changes were made. The images or other third party material in this article are included in the article's Creative Commons licence, unless indicated otherwise in a credit line to the material. If material is not included in the article's Creative Commons licence and your intended use is not permitted by statutory regulation or exceeds the permitted use, you will need to obtain permission directly from the copyright holder. To view a copy of this licence, visit http://creativecommons.org/licenses/by/4.0/ The Creative Commons Public Domain Dedication waiver (http://creativecommons.org/publicdomain/zero/1.0/) applies to the data made available in this article, unless otherwise stated in a credit line to the data. 
<smiles>O=C1CCC(N2C(=O)c3ccccc3C2=O)C(=O)N1</smiles>

Thalidomide<smiles>Nc1cccc2c1CN(C1CCC(=O)NC1=O)C2=O</smiles>

Lenalidomide<smiles>Nc1cccc2c1C(=O)N(C1CCC(=O)NC1=O)C2=O</smiles>

Pomalidomide<smiles>Cc1nc2cccc(N)c2c(=O)n1C1CCC(=O)NC1=O</smiles>

CC-122<smiles>N#Cc1ccc(N2CCN(Cc3ccc(COc4cccc5c4CN(C4CCC(=O)NC4=O)C5=O)cc3)CC2)c(F)c1</smiles><smiles>Cc1ccc(NC(=O)NCc2ccc3c(c2)CN(C2CCC(=O)NC2=O)C3=O)cc1Cl</smiles><smiles>O=C1CCC(N2Cc3cc(CNC(=O)C(F)(F)c4ccc(Cl)cc4)ccc3C2=O)C(=O)N1</smiles>

CC-90009

introduce genome-wide CRISPR screenings as a tool that can identify regulatory networks of IMiD sensitivity.

\section{Mechanism of IMiD activity}

CRBN, the primary cellular target of IMiDs [42], is a substrate receptor of CRL4, an E3 ubiquitin ligase complex consisting of Cullin $4 \mathrm{~A} / 4 \mathrm{~B}$, DNA damage-binding protein 1 (DDB1) and a small RING protein (RBX) [43]. IMiDs hijack the CRL4 ${ }^{\text {CRBN }}$ E3 ligase to ubiquitinate and degrade two essential lymphoid transcription factors, IKZF1 (Ikaros) and IKZF3 (Aiolos), which leads to the downregulation of IRF4 and MYC, resulting in the toxicity of MM cells $[44,45]$. Lenalidomide can bind the CRL4 ${ }^{\text {CRBN }}$ E3 ligase to induce ubiquitination and degradation of CK1 $\alpha$, accounting for its efficacy in $\operatorname{del}(5 q)$ MDS [46]. A number of other neosubstrates of IMiDs have been identified using proteomics analysis [47, 48]. Furthermore, the degradation of SALL4, PLZF and P63 proteins was reported to be correlated with thalidomideinduced malformations [48-51]. Thus, this class of compounds are also called CRBN E3 ligase modulators (CELMoDs). IMiDs represent the first class of drugs that function by inducing the degradation of cellular proteins (Fig. 2), which has important implications for the design of novel therapeutic compounds.

\section{Overview of emerging regulators of sensitivity to immunomodulatory drugs}

Since IMiDs bind the CRL4 ${ }^{\mathrm{CRBN}}$ E3 ligase to ubiquitinate and degrade disease-related proteins, the components of the CRL4 ${ }^{\text {CRBN }}$ E3 ligase and its activity are hypothesized to be essential for the antitumor activity of IMiDs. Recently, emerging evidence has shown the significance of CRL4 ${ }^{\mathrm{CRBN}}$ components for IMiD sensitivity, together with other cellular molecules and pathways.

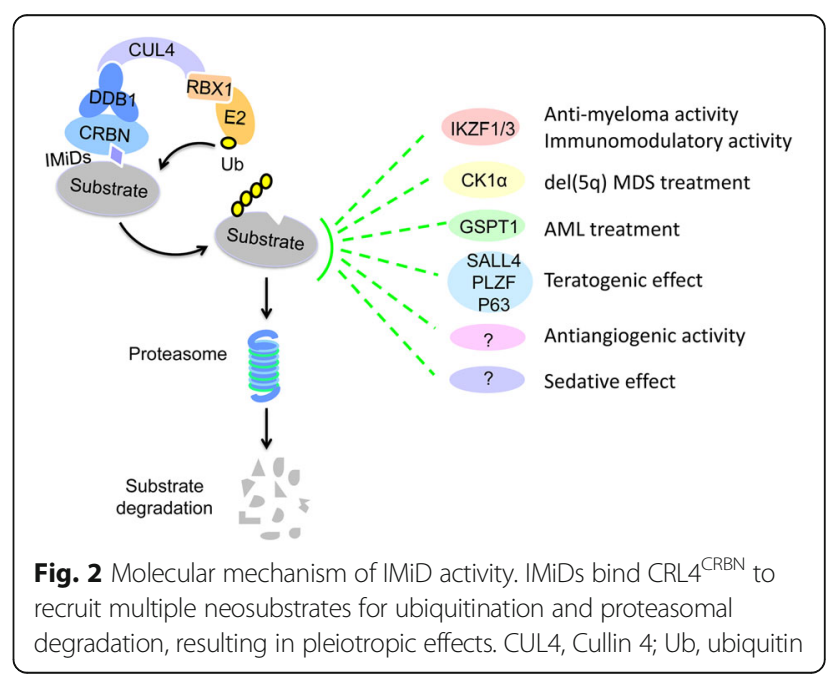




\section{CRBN}

As the primary target of IMiDs, CRBN was reported to be essential for the activity of IMiDs. CRBN knockdown leads to resistance to lenalidomide and pomalidomide in MM cell lines [31]. In addition, lenalidomide- or pomalidomide-resistant MM cells generated by incubation with gradually increasing concentrations of lenalidomide/pomalidomide show a significant decrease in CRBN protein levels [31, 52], suggesting an important role of CRBN in acquired IMiD resistance.

According to several clinical observations, high expression of CRBN has been reported to correlate with improved clinical response to IMiDs in MM patients [32, 33]. In addition, targeted sequencing data have shown that MM patients resistant to IMiDs frequently harbor $C R B N$ mutations [53]. CRBN alterations, including point mutations, copy loss/structural variations and an exon 10 splice variant transcript, have been found in lenalidomide- or pomalidomide-resistant MM patients [54]. Moreover, approximately one-third of MM patients who are refractory to pomalidomide are reported to carry genetic alterations in CRBN [54].

High expression of CRBN is associated with increased clinical efficacy of lenalidomide in $\operatorname{del}(5 \mathrm{q})$ MDS, while a decrease in CRBN expression correlates with loss of response and disease progression [55]. CRBN expression can also predict clinical response in CLL patients treated with IMiD-based therapy [56].

The above evidence indicates that CRBN expression is required for the antitumor activity of IMiDs. However, a lack of CRBN mutations or downregulation of CRBN expression levels has been reported in three MM cell lines intrinsically resistant to IMiDs [57]. In addition, a study reported that only one out of five MM patients refractory to lenalidomide showed significantly low expression of CRBN before treatment [58], indicating that factors other than CRBN might regulate intrinsic resistance to IMiDs.

\section{CRL4 and IKZF1/3}

As IMiDs function through hijacking CRL4 ${ }^{\text {CRBN }}$ E3 ligase to target neosubstrates like IKZF1/3 for ubiquitination and degradation, the expression of these components is supposed to be a necessity. Cullin 4 proteins consist of two homogenous members, Cullin $4 \mathrm{~A}$ and Cullin 4B, which serve as scaffolds for the CRL4 E3 ligase [43]. Mounting evidence has shown that Cullin $4 \mathrm{~A}$ and Cullin $4 \mathrm{~B}$ proteins can promote tumorigenesis in a number of malignancies [59-62]. Overexpression of Cullin $4 \mathrm{~A}$ in thalidomide-resistant prostate cancer cells can restore sensitivity to thalidomide, while knockdown of this gene in thalidomide-sensitive 22RV1 cells leads to drug resistance [34]. In addition, mutations in Cullin $4 B$ have been found in MM cases with acquired IMiD resistance, as have mutations in CRBN, DDB1 and IKZF1/3 [63].
IKZF1 (Q146H) and IKZF3 (Q147H) mutants are resistant to lenalidomide-induced degradation, and overexpression of either mutant protein can cause resistance to lenalidomide in MM1S cells [44, 45]. IKZF1 expression is decreased in IMiD-resistant MM cell lines, while MM patients with low expression of IKZF1 show a lack of response to IMiD treatment with shorter overall survival than patients with high expression of IKZF1 [64, 65]. IKZF3 expression predicts favorable response to lenalidomide and high expression of IKZF1/3 is correlated with longer median progression free survival in $M M$ [66]. Moreover, alterations in IKZF3 at diagnosis have been reported, suggesting that IKZF3 mutations may contribute to the pathogenesis of MM [63].

\section{RUNX proteins}

The RUNX family of transcription factors, composed of RUNX1, RUNX2 and RUNX3, are highly conserved and form heterodimers with $\mathrm{CBF} \beta$ to regulate target gene expression during development and hematopoiesis [6770]. Aberrations in $R U N X$ have been frequently identified in leukemia and solid tumors [71-74]. Recently, RUNX proteins have been found to interact and protect IKZF1 and IKZF3 proteins from lenalidomide-induced ubiquitination and degradation, resulting in the desensitization of MM cells to lenalidomide. Inhibition of RUNX proteins by the small molecule AI-10-104 leads to sensitization to lenalidomide in MM cell lines and primary MM cells [35], providing a reference for the combined use of RUNX inhibitors and IMiDs in MM treatment.

In contrast, loss of function of RUNX1 causes lenalidomide resistance in $\operatorname{del}(5 \mathrm{q})$ MDS cells, suggesting that RUNX1 function is required for lenalidomide sensitivity $[75,76]$. Recurrent variants of RUNX1 have been discovered in del(5q) MDS patients who become resistant to lenalidomide. Furthermore, RUNX1 forms a complex with GATA2 to drive megakaryocytic differentiation, which is required for lenalidomide efficacy [75]. Thus, RUNX proteins seem to have contrasting impacts on lenalidomide sensitivity in MM and del(5q) MDS cells.

\section{MEK/ERK}

Ras/RAF/MEK/ERK (mitogen-activated protein kinase, MAPK) signaling regulates cellular proliferation, differentiation and survival. Aberrant activation of the MAPK pathway is frequently observed in human cancers, and small molecules targeting this pathway have been approved to treat cancers, including melanoma, colorectal cancer and non-small-cell lung cancer [77, 78]. In a xenograft $\mathrm{MM}$ mouse model, acquired resistance to lenalidomide and pomalidomide is developed by continuous administration of pomalidomide-dexamethasone (PD), lenalidomide-dexamethasone (LD) or vehicle [79]. 
Upregulation of the MEK/ERK pathway has been found in IMiD-resistant cells, whose sensitivity to lenalidomide or pomalidomide can be restored by selumetinib, a small molecule MEK inhibitor [79].

\section{Wnt $/ \beta$-catenin signaling}

The conserved $\mathrm{Wnt} / \mathrm{\beta}$-catenin signaling pathway is a key regulator of development, the dysregulation of which is involved in tumorigenesis [80, 81]. Targeting $\mathrm{Wnt} / \beta$-catenin signaling has been proposed to improve the efficacy of cancer immunotherapy [82]. Dysregulation of Wnt/ $\beta$-catenin signaling was identified in a lenalidomide-resistant MM cell line [36]. Stimulation of the Wnt/ $/$-catenin pathway can reduce the antimyeloma activity of lenalidomide, while inhibition of $\beta$-catenin can restore sensitivity to lenalidomide [36]. This evidence suggests the possibility of targeting $W n t / \beta$-catenin signaling with inhibitors to alleviate IMiD resistance.

\section{Other factors}

Sensitivity to IMiDs has been reported to be affected by factors other than those discussed above. In IMiDresistant MM cells, dysregulation of a number of signaling mediators has been identified, including upregulation of IL-6/activation of STAT3 [83], increased genomewide DNA methylation [84], dysregulation of HIF-1 $\alpha$ [85, 86], dysregulation of CD44 [87], and decreased CD138 levels [88]. In addition, cellular antioxidative capacity can also affect sensitivity to lenalidomide in MM cells [89]. Activation of c-Abl kinase can potentiate the antimyeloma activity of lenalidomide [90]. RNAi and shRNA screenings have revealed that ribosomal protein S6 kinase (RSK2) and karyopherin beta 1 (KPNB1) are required for lenalidomide and pomalidomide sensitivity in MM cells, respectively [40, 41], while G proteincoupled receptor 68 (GPR68) is essential for lenalidomide sensitivity in del(5q) MDS cells [91].

IMiDs can target the CRL4 ${ }^{\text {CRBN }}$ E3 ligase to induce the degradation of specific proteins, and each of these compounds has a different spectrum of neosubstrates $[29,47,48]$, most of which share a common structural motif containing a key glycine [47, 92-95]. Distinct patterns of substrate specificity may explain the diversity in clinical activity and toxicity of these drugs. For example, degradation of CK1 $\alpha$ is a key event for lenalidomide efficacy in del(5q) MDS [46], while GSPT1 degradation is deemed to account for anti-AML activity of CC-885 and CC-90009 [25, 28]. A recent study showed that different neosubstrates compete for CRBN E3 ligase binding in the presence of IMiDs [96]. In this way, IMiD sensitivity is determined by the interplay between the CRBN E3 ligase and a number of potential neosubstrates [96], supporting the key role of CRBN expression in IMiD sensitivity.

\section{Genome-wide CRISPR screenings as a tool to identify genes required for IMiD sensitivity CRISPR genome editing and application}

The CRISPR-Cas system, derived from the prokaryotic adaptive immune system, has been modified to be a powerful tool in targeted genome editing [97-99]. CRIS PR-Cas9 genome editing is now widely used to generate gene-engineered cell lines and animals in laboratories worldwide [97, 98, 100]. Furthermore, CRISPR-mediated knockout of TCR and HLA class I molecules contributes to the generation of universal CAR-T cells [101-104]. Recent attempts have been made to use the CRISPR-Cas system therapeutically, especially in genetic disorders related to single gene mutations, including sickle cell anemia, cystic fibrosis and Huntington's chorea [105, 106].

In addition to its utility for research on single gene modifications, the CRISPR-Cas system has been applied for large-scale functional screening in genomic, transcriptomic or epigenetic research [107-110]. Genomewide CRISPR-Cas9 screening has been established to search for critical genes involved in drug resistance (Fig. 3a) [107]. Recently, genome-scale CRISPR screenings have been carried out to identify essential genes required for IMiD sensitivity in MM, primary effusion lymphoma (PEL) and AML [37-39].

\section{CRISPR-Cas9 screenings to identify genes required for IMiD sensitivity}

In one CRISPR-Cas9 screen, a library of sgRNAs targeting 19,050 genes and 1,000 control sgRNAs were introduced into MM1S cells, which were then incubated with lenalidomide or DMSO. Then, these cells were collected and analyzed using next-generation sequencing to identify genes required for lenalidomide activity in MM cells [37]. Among the top 30 genes, 17 were related to CRL4 E3 ligases, including $C R B N, D D B 1$, subunits of the COP9 signalosome (CSN), CAND1, UBE2G1 and $U B E 2 D 3$ [37]. In another CRISPR-Cas9 screen to identify genes required for pomalidomide activity in MM1S cells, a similar subset of targets was discovered [38]. The genes essential for IMiD activity in MM cells are summarized in Fig. 3b.

IMiDs have shown significant efficacy in PEL, a nonHodgkin B cell lymphoma [111, 112]. A CRISPR-Cas9 screen was conducted in PEL cells to search for genes essential for the activities of lenalidomide, pomalidomide and CC-122 [39]. According to the results, components of the CRL4 machinery were again identified, including CRBN, Cullin 4 A/4B, UBE2G1 and SENP8, together with other targets [39].

CC-90009, a new CRBN modulator, has shown notable efficacy in AML by selectively inducing degradation of GSPT1. CC-90009 promotes apoptosis of leukemia stem 


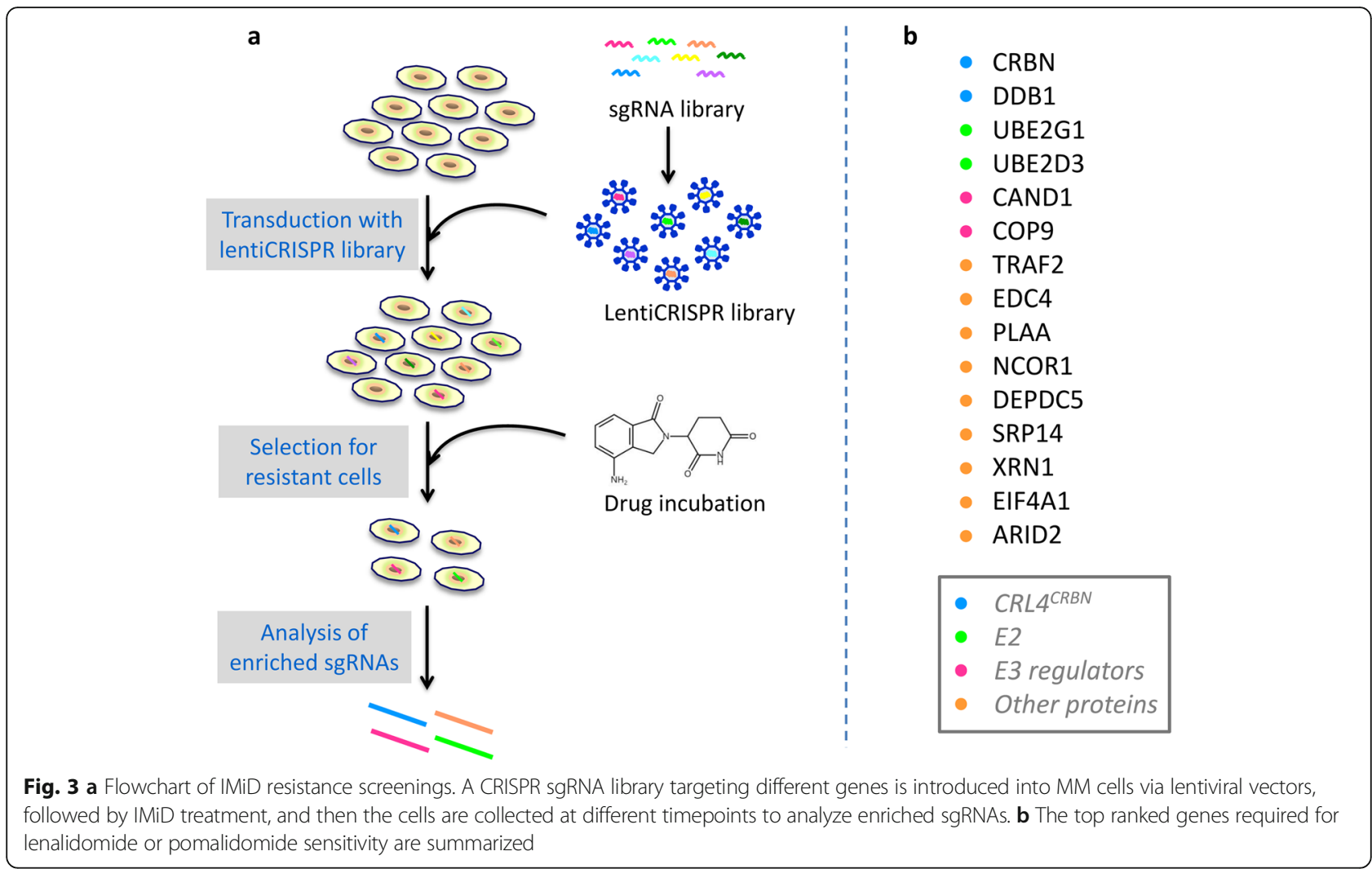

cells in xenografting of 35 primary AML samples, regardless of the adverse risk features [28]. Based on the promising efficacy, CC-90009 has entered clinical trials for AML and MDS (Table 1). A CRISPR-Cas9 screen in U937 cells has revealed essential genes for the efficacy of CC-90009, including subunits of CRL4 ${ }^{\text {CRBN }}$ E3 ligase, CSN, CAND1, ILF2/ILF3 [28].

In summary, components of the CRL4 E3 ligase are required for IMiD sensitivity, which is consistent with the mechanism of these compounds. Furthermore, regulators of CRL4 E3 ligase activity for example, CSN, also affect IMiD activity. Deletion of CSN causes a significant decrease in CRBN protein levels in MM cells, which can explain the IMiD resistance in CSN-deleted cells [38]. ATrich interactive domain 2 (ARID2), a component of the polybromo-BRG1-associated factors (PBAF) chromatinremodeling complex, was also identified to be required for pomalidomide activity in MM cells [38], which was recently verified by the discovery of ARID2 as a pomalidomide-induced neosubstrate [113]. Degradation of ARID2 causes downregulation of MYC, leading to the death of MM cells [113]. These data demonstrate the powerful function of CRISPR screens in the discovery of regulatory networks of drug sensitivity.

\section{Conclusion and perspective}

As the primary target of IMiDs, CRBN is required for IMiD sensitivity. Due to the rapid development of biotechnology tools such as CRISPR genome editing, many other regulators of IMiD sensitivity have been identified. CRL4 components such as Cullin 4 A/4B, DDB1 and E2 and regulators of E3 ligase are also required for IMiD sensitivity. Degradation of IKZF1/3 are essential for antimyeloma activity of IMiDs in MM. RUNX1 and GATA2 are required for lenalidomide activity in $\operatorname{del}(5 \mathrm{q})$ MDS. Mutations in components of CRL4 ${ }^{\text {CRBN }}$ E3 ligase, mainly CRBN itself, IKZF1/3 and RUNX have been identified in IMiD-resistant cells, together with dysregulation of

Table 1 Clinical trials of CC-90009

\begin{tabular}{|c|c|c|c|}
\hline Phase & Conditions & Interventions & NCT ID \\
\hline 1 & Healthy Volunteer & $\begin{array}{l}\text { CC-90009 } \\
\text { Radiation: [14 C] }\end{array}$ & NCT04297124 \\
\hline 1 & AML, MDS & CC-90009 & NCT02848001 \\
\hline 1,2 & AML & CC-90009, Venetoclax, Azacitidine, Gilteritinib & NCT04336982 \\
\hline
\end{tabular}

Abbreviation: $A M L$ acute myeloid leukemia, MDS myelodysplastic syndrome 
MEK/ERK, Wnt/ $\beta$-catenin and IL-6/STAT3 pathways (Fig. 4). As IMiDs have also shown notable efficacy in different hematological malignancies such as CLL, DLBCL and AML, which have diverse genetic features, disease-specific regulators of IMiD sensitivity might be identified by future studies.

New generation of IMiDs are under clinical development. CC-122 is now in phase $1 / 2$ trials for hematological malignancies, including DLBCL and MM [29]. The most common treatment-emergent adverse events (TEAEs) are neutropenia, thrombocytopenia and anemia $[21,22,114-116]$. CC-220 has shown significant efficacy in systemic lupus erythematosus (SLE) and relapsed/refractory MM (RRMM) and now under phase 1/ 2 studies [24, 117]. Neutropenia, infection and thrombocytopenia have been reported following CC-220 administration [118-120]. CC-92480 can induce deeper degradation of IKZF1/3, showing therapeutic advantage in lenalidomide-resistant MM cells with little effect on the viability of normal peripheral blood mononuclear cells [27]. CC-92480 is now under phase $1 / 2$ clinical trials mainly for MM. CC-885 has anti-proliferation activity in a broad range of tumor cell lines and significant anti-AML potency by the degradation of GSPT1 [25]. CC-90009 induces the degradation of GSPT1 with higher selectivity and now in phase $1 / 2$ clinical studies for AML and MDS. As these CRBN modulators function through a similar mechanism, the understanding of regulatory networks of $\mathrm{IMiD}$ sensitivity may provide reference for the development of new IMiDs.

Proteolysis-targeting chimeras (PROTACs) are bifunctional molecules that can target proteins for degradation via the ubiquitin-proteasome pathway. A typical PROTAC molecule contains a ligand for the protein of interest covalently linked to a moiety of an E3 ubiquitin ligase [121-124]. Since IMiDs repurpose the CRL4 ${ }^{\text {CRBN }}$ E3 ligase to ubiquitinate and degrade a number of cellular proteins, these molecules have been frequently used in the design of PROTACs. In this way, IMiDs have been

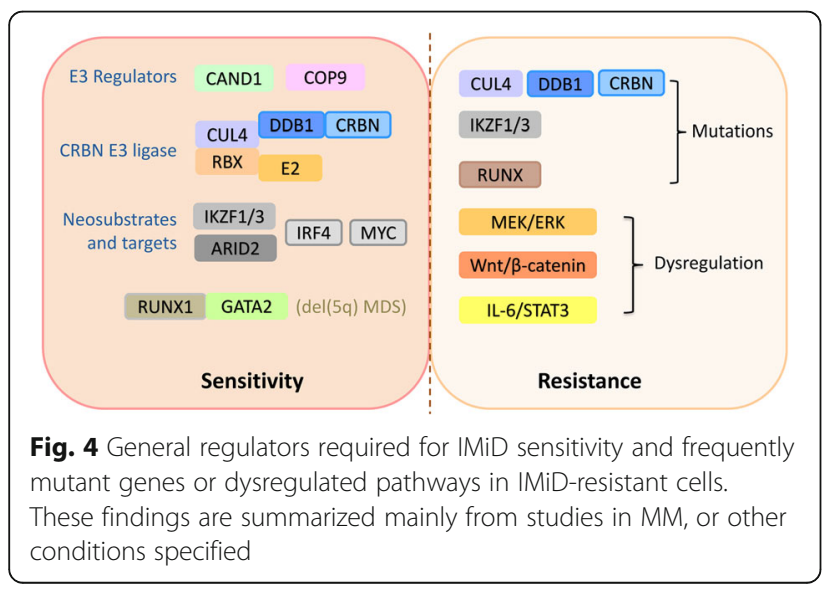

linked to ligands of BTK, BCR-Abl, BRD4 and other targets to generate PROTACs that can degrade these oncoproteins [125-127]. Targeting protein for degradation by PROTACs has emerged as a powerful therapeutic strategy in cancer treatment. The discovery of mechanism of IMiDs facilitates the development of PROTACs by providing more choices on E3 ligase utilization. Thus, the delineation of key regulators of IMiD sensitivity may promote the development of IMiD-based PROTACs.

\section{Abbreviations \\ AML: Acute myeloid leukemia; BRD4: Bromodomain-containing protein 4; ARID2: AT-rich interactive domain 2; BTK: Bruton's tyrosine kinase: \\ CELMoDs: CRBN E3 ligase modulators; CSN: COP9 signalosome; CRL4: Cullin- RING ligase 4; DLBCL: Diffuse large B-cell lymphoma; FL: Follicular lymphoma; GPR68: G protein-coupled receptor 68; IMiDs: Immunomodulatory drugs; KPNB1: Karyopherin beta 1; MCL: Mantle cell lymphoma; \\ MDS: Myelodysplastic syndrome; MM: Multiple myeloma; PEL: Primary effusion lymphoma; PROTACs: Proteolysis-targeting chimeras; RRMM: Relapsed/refractory MM; RSK2: Ribosomal protein S6 kinase: SLE: Systemic lupus erythematosus; TEAEs: Treatment-emergent adverse events; VHL: Von Hippel-Lindau}

\section{Acknowledgements}

Not applicable.

\section{Authors' contributions}

SW and SG conceived, drafted and revised the manuscript. ZL prepared figure 1. All authors read and approved the final manuscript.

\section{Funding}

The study was supported by the National Natural Science Foundation of China (No. 81800204) and Medical Science and Technology Foundation of Henan Province (No. LHGJ20200178).

\section{Availability of data and materials}

The material supporting the conclusion of this review has been included within the article.

\section{Declarations}

Ethics approval and consent to participate

Not applicable.

\section{Consent for publication}

Not applicable.

\section{Competing interests}

The authors declare that they have no competing interests.

Received: 15 March 2021 Accepted: 18 May 2021

Published online: 05 June 2021

\section{References}

1. Sampaio EP. Thalidomide selectively inhibits tumor necrosis factor alpha production by stimulated human monocytes. J Exp Med. 1991;173(3):699703.

2. Corral LG, Haslett PA, Muller GW, Chen R, Wong LM, Ocampo CJ, Patterson RT, Stirling DI, Kaplan G. Differential cytokine modulation and T cell activation by two distinct classes of thalidomide analogues that are potent inhibitors of TNF-alpha. J Immunol. 1999;163(1):380-6.

3. Haslett PA, Klausner JD, Makonkawkeyoon S, Moreira A, Metatratip P, Boyle B, Kunachiwa W, Maneekarn N, Vongchan P, Corral LG, et al. Thalidomide stimulates T cell responses and interleukin 12 production in HIV-infected patients. AIDS Res Hum Retroviruses. 1999;15(13):1169-79.

4. Davies FE, Raje N, Hideshima T, Lentzsch S, Young G, Tai YT, Lin B, Podar K, Gupta D, Chauhan D, et al. Thalidomide and immunomodulatory derivatives augment natural killer cell cytotoxicity in multiple myeloma. Blood. 2001; 98(1):210-6. 
5. Singhal S, Mehta J, Desikan R, Ayers D, Roberson P, Eddlemon P, Munshi N, Anaissie E, Wilson C, Dhodapkar M, et al. Antitumor activity of thalidomide in refractory multiple myeloma. N Engl J Med. 1999;341(21):1565-71.

6. Dimopoulos M, Spencer A, Attal M, Prince HM, Harousseau JL, Dmoszynska A, San Miguel J, Hellmann A, Facon T, Foa R, et al. Lenalidomide plus dexamethasone for relapsed or refractory multiple myeloma. N Engl J Med. 2007;357(21):2123-32.

7. Schey SA, Fields P, Bartlett JB, Clarke IA, Ashan G, Knight RD, Streetly M, Dalgleish AG. Phase I study of an immunomodulatory thalidomide analog, CC-4047, in relapsed or refractory multiple myeloma. J Clin Oncol. 2004; 22(16):3269-76.

8. Dimopoulos M, Wang M, Maisnar V, Minarik J, Bensinger W, Mateos MV, Obreja M, Blaedel J, Moreau P. Response and progression-free survival according to planned treatment duration in patients with relapsed multiple myeloma treated with carfilzomib, lenalidomide, and dexamethasone (KRd) versus lenalidomide and dexamethasone (Rd) in the phase III ASPIRE study. J Hematol Oncol. 2018;11(1):49.

9. Dimopoulos MA, Oriol A, Nahi H, San-Miguel J, Bahlis NJ, Usmani SZ, Rabin N, Orlowski RZ, Komarnicki M, Suzuki K, et al. Daratumumab, Lenalidomide, and Dexamethasone for Multiple Myeloma. N Engl J Med. 2016;375(14): 1319-31.

10. List A, Dewald G, Bennett J, Giagounidis A, Raza A, Feldman E, Powell B, Greenberg P, Thomas D, Stone R, et al. Lenalidomide in the myelodysplastic syndrome with chromosome 5q deletion. N Engl J Med. 2006;355(14):1456-65.

11. List A, Kurtin S, Roe DJ, Buresh A, Mahadevan D, Fuchs D, Rimsza L, Heaton $\mathrm{R}$, Knight $\mathrm{R}$, Zeldis JB. Efficacy of lenalidomide in myelodysplastic syndromes. N Engl J Med. 2005;352(6):549-57.

12. Habermann TM, Lossos IS, Justice G, Vose JM, Wiernik PH, McBride K, Wride K, Ervin-Haynes A, Takeshita K, Pietronigro D, et al. Lenalidomide oral monotherapy produces a high response rate in patients with relapsed or refractory mantle cell lymphoma. Br J Haematol. 2009;145(3):344-9.

13. Zinzani PL, Vose JM, Czuczman MS, Reeder CB, Haioun C, Polikoff J, Tilly H, Zhang L, Prandi K, Li J, et al. Long-term follow-up of lenalidomide in relapsed/refractory mantle cell lymphoma: subset analysis of the NHL-003 study. Ann Oncol. 2013;24(11):2892-7.

14. Witzig TE, Luigi Zinzani P, Habermann TM, Tuscano JM, Drach J, Ramchandren R, Kalayoglu Besisik S, Takeshita K, Casadebaig Bravo ML, Zhang $L$, et al. Long-term analysis of phase II studies of single-agent lenalidomide in relapsed/refractory mantle cell lymphoma. Am J Hematol. 2017;92(10):E575-E83.

15. Ladha A, Zhao J, Epner EM, Pu JJ. Mantle cell lymphoma and its management: where are we now? Exp Hematol Oncol. 2019;8(1):2

16. Chanan-Khan A, Miller KC, Musial L, Lawrence D, Padmanabhan S, Takeshita K, Porter CW, Goodrich DW, Bernstein ZP, Wallace P, et al. Clinical efficacy of lenalidomide in patients with relapsed or refractory chronic lymphocytic leukemia: results of a phase II study. J Clin Oncol. 2006;24(34):5343-9.

17. Ferrajoli A, Lee BN, Schlette EJ, O'Brien SM, Gao H, Wen S, Wierda WG, Estrov Z, Faderl S, Cohen EN, et al. Lenalidomide induces complete and partial remissions in patients with relapsed and refractory chronic lymphocytic leukemia. Blood. 2008;111(11):5291-7.

18. Badoux XC, Keating MJ, Wen S, Wierda WG, O'Brien SM, Faderl S, Sargent R, Burger JA, Ferrajoli A. Phase II study of lenalidomide and rituximab as salvage therapy for patients with relapsed or refractory chronic lymphocytic leukemia. J Clin Oncol. 2013;31(5):584-91.

19. Hagner PR, Man HW, Fontanillo C, Wang M, Couto S, Breider M, Bjorklund C, Havens CG, Lu G, Rychak E, et al. CC-122, a pleiotropic pathway modifier, mimics an interferon response and has antitumor activity in DLBCL. Blood. 2015;126(6):779-89.

20. Cubillos-Zapata C, Cordoba R, Avendano-Ortiz J, Arribas-Jimenez C, Hernandez-Jimenez E, Toledano V, Villaescusa T, Moreno V, Lopez-Collazo E. CC-122 immunomodulatory effects in refractory patients with diffuse large B-cell lymphoma. Oncoimmunology. 2016;5(12):e1231290

21. Carpio C, Bouabdallah R, Ysebaert L, Sancho JM, Salles G, Cordoba R, Pinto A, Gharibo M, Rasco D, Panizo C, et al. Avadomide monotherapy in relapsed/refractory DLBCL: safety, efficacy, and a predictive gene classifier. Blood. 2020;135(13):996-1007.

22. Michot JM, Bouabdallah R, Vitolo U, Doorduijn JK, Salles G, Chiappella A, Zinzani PL, Bijou F, Kersten MJ, Sarmiento R, et al. Avadomide plus obinutuzumab in patients with relapsed or refractory B-cell non-Hodgkin lymphoma (CC-122-NHL-001): a multicentre, dose escalation and expansion phase 1 study. Lancet Haematol. 2020;7(9):e649-e59.
23. Amatangelo M, Bjorklund CC, Kang J, Polonskaia A, Viswanatha S, Thakurta A. Iberdomide (CC-220) Has Synergistic Anti-Tumor and Immunostimulatory Activity Against Multiple Myeloma in Combination with Both Bortezomib and Dexamethasone, or in Combination with Daratumumab in Vitro. Blood. 2018; 132(Supplement 1): 1935.

24. Bjorklund CC, Kang J, Amatangelo M, Polonskaia A, Katz M, Chiu H, Couto S, Wang $M$, Ren Y, Ortiz M, et al. Iberdomide (CC-220) is a potent cereblon E3 ligase modulator with antitumor and immunostimulatory activities in enalidomide- and pomalidomide-resistant multiple myeloma cells with dysregulated CRBN. Leukemia. 2020;34(4):1197-201.

25. Matyskiela ME, Lu G, Ito T, Pagarigan B, Lu CC, Miller K, Fang W, Wang NY, Nguyen D, Houston J, et al. A novel cereblon modulator recruits GSPT1 to the CRL4(CRBN) ubiquitin ligase. Nature. 2016;535(7611):252-7.

26. Hao BB, Li XJ, Jia XL, Wang YX, Zhai LH, Li DZ, Liu J, Zhang D, Chen YL, Xu $\mathrm{YH}$, et al. The novel cereblon modulator CC-885 inhibits mitophagy via selective degradation of BNIP3L. Acta Pharmacol Sin. 2020;41(9):1246-54.

27. Hansen JD, Correa M, Nagy MA, Alexander M, Plantevin V, Grant V, Whitefield B, Huang D, Kercher T, Harris R, et al. Discovery of CRBN E3 Ligase Modulator CC-92480 for the Treatment of Relapsed and Refractory Multiple Myeloma. J Med Chem. 2020;63(13):6648-76.

28. Surka C, Jin L, Mbong N, Lu CC, Jang IS, Rychak E, Mendy D, Clayton T, Tindall E, Hsu C, et al. CC-90009, a novel cereblon E3 ligase modulator, targets acute myeloid leukemia blasts and leukemia stem cells. Blood. 2021; 137(5):661-77.

29. Gao S, Wang S, Song Y. Novel immunomodulatory drugs and neosubstrates. Biomark Res. 2020;8(1):2.

30. Piccolomo A, Schifone CP, Strafella V, Specchia G, Musto P, Albano F. Immunomodulatory Drugs in Acute Myeloid Leukemia Treatment. Cancers (Basel). 2020;12(9):2528.

31. Zhu YX, Braggio E, Shi CX, Bruins LA, Schmidt JE, Van Wier S, Chang XB, Bjorklund CC, Fonseca R, Bergsagel PL, et al. Cereblon expression is required for the antimyeloma activity of lenalidomide and pomalidomide. Blood. 2011;118(18):4771-9.

32. Broyl A, Kuiper $R$, van Duin $M$, van der Holt B, el Jarari $L$, Bertsch $U$, Zweegman S, Buijs A, Hose D, Lokhorst HM, et al. High cereblon expression is associated with better survival in patients with newly diagnosed multiple myeloma treated with thalidomide maintenance. Blood. 2013;121(4):624-7.

33. Heintel D, Rocci A, Ludwig H, Bolomsky A, Caltagirone S, Schreder M, Pfeifer $\mathrm{S}$, Gisslinger $\mathrm{H}$, Zojer $\mathrm{N}$, Jager $\mathrm{U}$, et al. High expression of cereblon (CRBN) is associated with improved clinical response in patients with multiple myeloma treated with lenalidomide and dexamethasone. Br J Haematol. 2013;161(5):695-700

34. Ren S, Xu C, Cui Z, Yu Y, Xu W, Wang F, Lu J, Wei M, Lu X, Gao X, et al. Oncogenic CUL4A determines the response to thalidomide treatment in prostate cancer. J Mol Med (Berl). 2012;90(10):1121-32.

35. Zhou N, Gutierrez-Uzquiza A, Zheng XY, Chang R, Vogl DT, Garfall AL, Bernabei L, Saraf A, Florens L, Washburn MP, et al. RUNX proteins desensitize multiple myeloma to lenalidomide via protecting IKZFs from degradation. Leukemia. 2019;33(8):2006-21.

36. Bjorklund CC, Ma W, Wang ZQ, Davis RE, Kuhn DJ, Kornblau SM, Wang M, Shah JJ, Orlowski RZ. Evidence of a role for activation of Wnt/beta-catenin signaling in the resistance of plasma cells to lenalidomide. J Biol Chem. 2011;286(13):11009-20.

37. Sievers QL, Gasser JA, Cowley GS, Fischer ES, Ebert BL. Genome-wide screen identifies cullin-RING ligase machinery required for lenalidomide-dependent CRL4(CRBN) activity. Blood. 2018;132(12):1293-303.

38. Liu J, Song T, Zhou W, Xing L, Wang S, Ho M, Peng Z, Tai YT, Hideshima T, Anderson $\mathrm{KC}$, et al. A genome-scale CRISPR-Cas9 screening in myeloma cells identifies regulators of immunomodulatory drug sensitivity. Leukemia. 2019:33(1):171-80.

39. Patil A, Manzano M, Gottwein E. Genome-wide CRISPR screens reveal genetic mediators of cereblon modulator toxicity in primary effusion lymphoma. Blood Adv. 2019;3(14):2105-17.

40. Tateno S, lida M, Fujii S, Suwa T, Katayama M, Tokuyama H, Yamamoto J, Ito T, Sakamoto S, Handa H, et al. Genome-wide screening reveals a role for subcellular localization of CRBN in the anti-myeloma activity of pomalidomide. Sci Rep. 2020;10(1):4012.

41. Zhu YX, Yin $H$, Bruins LA, Shi CX, Jedlowski $P$, Aziz M, Sereduk C, Kortuem KM, Schmidt JE, Champion M, et al. RNA interference screening identifies lenalidomide sensitizers in multiple myeloma, including RSK2. Blood. 2015; 125(3):483-91. 
42. Ito T, Ando H, Suzuki T, Ogura T, Hotta K, Imamura Y, Yamaguchi Y, Handa $\mathrm{H}$. Identification of a primary target of thalidomide teratogenicity. Science. 2010;327(5971):1345-50.

43. Jackson S, Xiong Y. CRL4s: the CUL4-RING E3 ubiquitin ligases. Trends Biochem Sci. 2009;34(11):562-70.

44. Lu G, Middleton RE, Sun H, Naniong M, Ott CJ, Mitsiades CS, Wong KK Bradner JE, Kaelin WG. Jr. The myeloma drug lenalidomide promotes the cereblon-dependent destruction of Ikaros proteins. Science. 2014;343(6168): 305-9.

45. Kronke J, Udeshi ND, Narla A, Grauman P, Hurst SN, McConkey M, Svinkina T, Heckl D, Comer E, Li X, et al. Lenalidomide causes selective degradation of IKZF1 and IKZF3 in multiple myeloma cells. Science. 2014;343(6168):301-5.

46. Kronke J, Fink EC, Hollenbach PW, MacBeth KJ, Hurst SN, Udeshi ND, Chamberlain PP, Mani DR, Man HW, Gandhi AK, et al. Lenalidomide induces ubiquitination and degradation of CK1alpha in del(5q) MDS. Nature. 2015; 523(7559):183-8

47. Sievers QL, Petzold G, Bunker RD, Renneville A, Slabicki M, Liddicoat BJ, Abdulrahman W, Mikkelsen T, Ebert BL, Thoma NH. Defining the human $\mathrm{C} 2 \mathrm{H} 2$ zinc finger degrome targeted by thalidomide analogs through CRBN. Science. 2018;362(6414):eaat0572.

48. Donovan KA, An J, Nowak RP, Yuan JC, Fink EC, Berry BC, Ebert BL, Fischer ES. Thalidomide promotes degradation of SALL4, a transcription factor implicated in Duane Radial Ray syndrome. Elife. 2018; 7. https://doi.org/10. 7554/elife.38430.

49. Matyskiela ME, Couto S, Zheng X, Lu G, Hui J, Stamp K, Drew C, Ren Y, Wang M, Carpenter A, et al. SALL4 mediates teratogenicity as a thalidomidedependent cereblon substrate. Nat Chem Biol. 2018;14(10):981-7.

50. Yamanaka S, Murai H, Saito D, Abe G, Tokunaga E, Iwasaki T, Takahashi H, Takeda H, Suzuki T, Shibata N, et al. Thalidomide and its metabolite 5hydroxythalidomide induce teratogenicity via the cereblon neosubstrate PLZF. EMBO J. 2021: e2020105375.

51. Asatsuma-Okumura T, Ando H, De Simone M, Yamamoto J, Sato T, Shimizu N, Asakawa K, Yamaguchi Y, Ito T, Guerrini L, et al. p63 is a cereblon substrate involved in thalidomide teratogenicity. Nat Chem Biol. 2019;15(11): 1077-84.

52. Lopez-Girona A, Mendy D, Ito T, Miller K, Gandhi AK, Kang J, Karasawa S, Carmel G, Jackson P, Abbasian M, et al. Cereblon is a direct protein target for immunomodulatory and antiproliferative activities of lenalidomide and pomalidomide. Leukemia. 2012;26(11):2326-35.

53. Kortum KM, Mai EK, Hanafiah NH, Shi CX, Zhu YX, Bruins L, Barrio S,

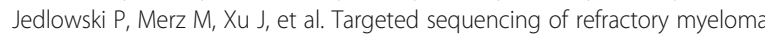
reveals a high incidence of mutations in CRBN and Ras pathway genes. Blood. 2016;128(9):1226-33.

54. Gooding S, Ansari-Pour N, Towfic F, Ortiz Estevez M, Chamberlain PP, Tsai $K T$, Flynt $E$, Hirst M, Rozelle D, Dhiman P, et al. Multiple cereblon genetic changes are associated with acquired resistance to lenalidomide or pomalidomide in multiple myeloma. Blood. 2021;137(2):232-7.

55. Jonasova A, Bokorova R, Polak J, Vostry M, Kostecka A, Hajkova H, Neuwirtova R, Siskova M, Sponerova D, Cermak J, et al. High level of fulllength cereblon mRNA in lower risk myelodysplastic syndrome with isolated $5 q$ deletion is implicated in the efficacy of lenalidomide. Eur J Haematol. 2015;95(1):27-34.

56. Jamroziak K, Szemraj J, Robak T, Tukiendorf A, Giannopoulos K. Cereblon expression predicts clinical response in chronic lymphocytic leukemia treated with a thalidomide/fludarabine regimen. Leuk Lymphoma. 2015; 56(3):808-10.

57. Thakurta A, Gandhi AK, Waldman MF, Bjorklund C, Ning Y, Mendy D, Schafer P, Lopez-Girona A, Lentzsch S, Schey SA, et al. Absence of mutations in cereblon (CRBN) and DNA damage-binding protein 1 (DDB1) genes and significance for IMiD therapy. Leukemia. 2014;28(5):1129-31.

58. Dimopoulos K, Fibiger Munch-Petersen H, Winther Eskelund C, Dissing Sjo L, Ralfkiaer E, Gimsing P, Gronbaek K. Expression of CRBN, IKZF1, and IKZF3 does not predict lenalidomide sensitivity and mutations in the cereblon pathway are infrequent in multiple myeloma. Leuk Lymphoma. 2019;60(1): 180-8.

59. Jia L, Yan F, Cao W, Chen Z, Zheng H, Li H, Pan Y, Narula N, Ren X, Li H, et al. Dysregulation of CUL4A and CUL4B Ubiquitin Ligases in Lung Cancer. J Biol Chem. 2017;292(7):2966-78.

60. Hung MS, Mao JH, Xu Z, Yang CT, Yu JS, Harvard C, Lin YC, Bravo DT, Jablons DM, You L. Cul4A is an oncogene in malignant pleural mesothelioma. J Cell Mol Med. 2011;15(2):350-8.
61. Wang $Y$, Wen $M$, Kwon $Y, X u Y$, Liu $Y$, Zhang $P$, He X, Wang $Q$, Huang $Y$, Jen $K Y$, et al. CUL4A induces epithelial-mesenchymal transition and promotes cancer metastasis by regulating ZEB1 expression. Cancer Res. 2014;74(2): 520-31.

62. Yang Y, Liu R, Qiu R, Zheng Y, Huang W, Hu H, Ji Q, He H, Shang Y, Gong Y, et al. CRL4B promotes tumorigenesis by coordinating with SUV39H1/HP1/ DNMT3A in DNA methylation-based epigenetic silencing. Oncogene. 2015; 34(1):104-18.

63. Barrio S, Munawar U, Zhu YX, Giesen N, Shi CX, Via MD, Sanchez R, Bruins L, Demler T, Muller N, et al. IKZF1/3 and CRL4(CRBN) E3 ubiquitin ligase mutations and resistance to immunomodulatory drugs in multiple myeloma. Haematologica. 2020;105(5):e237-e41.

64. Zhu YX, Braggio E, Shi CX, Kortuem KM, Bruins LA, Schmidt JE, Chang XB, Langlais $P$, Luo $M$, Jedlowski $P$, et al. Identification of cereblon-binding proteins and relationship with response and survival after IMiDs in multiple myeloma. Blood. 2014;124(4):536-45.

65. Tachita T, Kinoshita S, Ri M, Aoki S, Asano A, Kanamori T, Yoshida T, Totani $\mathrm{H}$, Ito A, Kusumoto S, et al. Expression, mutation, and methylation of cereblon-pathway genes at pre- and post-lenalidomide treatment in multiple myeloma. Cancer Sci. 2020;111(4):1333-43.

66. Pourabdollah M, Bahmanyar M, Atenafu EG, Reece D, Hou J, Chang H. High IKZF1/3 protein expression is a favorable prognostic factor for survival of relapsed/refractory multiple myeloma patients treated with lenalidomide. J Hematol Oncol. 2016;9(1):123.

67. Sood R, Kamikubo Y, Liu P. Role of RUNX1 in hematological malignancies. Blood. 2017;129(15):2070-82.

68. de Bruijn M, Dzierzak E. Runx transcription factors in the development and function of the definitive hematopoietic system. Blood. 2017;129(15):2061-9.

69. Wang Q, Stacy T, Miller JD, Lewis AF, Gu T-L, Huang X, Bushweller JH, Bories J-C, Alt FW, Ryan G, et al. The CBF $\beta$ Subunit is Essential for CBFa2 (AML1) Function In Vivo. Cell. 1996;87(4):697-708.

70. Ogawa E, Inuzuka M, Maruyama M, Satake M, Naito-Fujimoto M, Ito Y, Shigesada K. Molecular cloning and characterization of PEBP2 beta, the heterodimeric partner of a novel Drosophila runt-related DNA binding protein PEBP2 alpha. Virology. 1993;194(1):314-31.

71. Ito Y, Bae SC, Chuang LS. The RUNX family: developmental regulators in cancer. Nat Rev Cancer. 2015;15(2):81-95.

72. Ng IKS, Lee J, Ng C, Kosmo B, Chiu L, Seah E, Mok MMH, Tan K, Osato M, Chng W-J, et al. Preleukemic and second-hit mutational events in an acute myeloid leukemia patient with a novel germline RUNX1 mutation. Biomark Res. 2018;6(1):16.

73. Bera R, Chiu MC, Huang YJ, Lin TH, Kuo MC, Shih LY. RUNX1 mutations promote leukemogenesis of myeloid malignancies in ASXL1-mutated leukemia. J Hematol Oncol. 2019;12(1):104.

74. Cohen-Solal KA, Boregowda RK, Lasfar A. RUNX2 and the PI3K/AKT axis reciprocal activation as a driving force for tumor progression. Mol Cancer. 2015;14(1):137.

75. Martinez-Hoyer S, Deng Y, Parker J, Jiang J, Mo A, Docking TR, Gharaee N, Li J, Umlandt $\mathrm{P}$, Fuller $\mathrm{M}$, et al. Loss of lenalidomide-induced megakaryocytic differentiation leads to therapy resistance in del(5q) myelodysplastic syndrome. Nat Cell Biol. 2020;22(5):526-33.

76. Drusbosky LM, Cogle CR. Identification of Lenalidomide Sensitivity and Resistance Mechanisms in Non-Del(5q) Myelodysplastic Syndromes. Int J Mol Sci. 2020;21(9):3323.

77. Yaeger R, Corcoran RB. Targeting Alterations in the RAF-MEK Pathway. Cancer Discov. 2019;9(3):329-41.

78. Yuan J, Dong X, Yap J, Hu J. The MAPK and AMPK signalings: interplay and implication in targeted cancer therapy. J Hematol Oncol. 2020;13(1):113.

79. Ocio EM, Fernandez-Lazaro D, San-Segundo L, Lopez-Corral L, Corchete LA, Gutierrez NC, Garayoa M, Paino T, Garcia-Gomez A, Delgado M, et al. In vivo murine model of acquired resistance in myeloma reveals differential mechanisms for lenalidomide and pomalidomide in combination with dexamethasone. Leukemia. 2015;29(3):705-14.

80. Nusse R, Clevers H. Wnt/ß-Catenin Signaling, Disease, and Emerging Therapeutic Modalities. Cell. 2017;169(6):985-99.

81. Pai SG, Carneiro BA, Mota JM, Costa R, Leite CA, Barroso-Sousa R, Kaplan JB, Chae YK, Giles FJ. Wnt/beta-catenin pathway: modulating anticancer immune response. J Hematol Oncol. 2017;10(1):101.

82. Wang B, Tian T, Kalland KH, Ke X, Qu Y. Targeting Wnt/beta-Catenin Signaling for Cancer Immunotherapy. Trends Pharmacol Sci. 2018;39(7): $648-58$. 
83. Zhu YX, Shi CX, Bruins LA, Wang X, Riggs DL, Porter B, Ahmann JM, de Campos $C B$, Braggio $E$, Bergsagel PL, et al. Identification of lenalidomide resistance pathways in myeloma and targeted resensitization using cereblon replacement, inhibition of STAT3 or targeting of IRF4. Blood Cancer J. 2019;9(2):19.

84. Dimopoulos K, Sogaard Helbo A, Fibiger Munch-Petersen H, Sjo L, Christensen J, Sommer Kristensen L, Asmar F, Hermansen NEU, O'Connel C, Gimsing P, et al. Dual inhibition of DNMTs and EZH2 can overcome both intrinsic and acquired resistance of myeloma cells to IMiDs in a cereblonindependent manner. Mol Oncol. 2018;12(2):180-95.

85. Ria R, Catacchio I, Berardi S, De Luisi A, Caivano A, Piccoli C, Ruggieri V, Frassanito MA, Ribatti D, Nico B, et al. HIF-1alpha of bone marrow endothelial cells implies relapse and drug resistance in patients with multiple myeloma and may act as a therapeutic target. Clin Cancer Res. 2014;20(4):847-58.

86. Storti $P$, Toscani $D$, Airoldi I, Marchica V, Maiga S, Bolzoni M, Fiorini E, Campanini N, Martella E, Mancini C, et al. The anti-tumoral effect of lenalidomide is increased in vivo by hypoxia-inducible factor (HIF)-1alpha inhibition in myeloma cells. Haematologica. 2016;101(3):e107-10.

87. Bjorklund CC, Baladandayuthapani V, Lin HY, Jones RJ, Kuiatse I, Wang H, Yang J, Shah JJ, Thomas SK, Wang M, et al. Evidence of a role for CD44 and cell adhesion in mediating resistance to lenalidomide in multiple myeloma: therapeutic implications. Leukemia. 2014;28(2):373-83.

88. Kawano Y, Fujiwara S, Wada N, Izaki M, Yuki H, Okuno Y, lyama K, Yamasaki $H$, Sakai A, Mitsuya $H$, et al. Multiple myeloma cells expressing low levels of CD138 have an immature phenotype and reduced sensitivity to lenalidomide. Int J Oncol. 2012;41(3):876-84.

89. Sebastian S, Zhu YX, Braggio E, Shi CX, Panchabhai SC, Van Wier SA, Ahmann GJ, Chesi M, Bergsagel PL, Stewart AK, et al. Multiple myeloma cells' capacity to decompose $\mathrm{H} 2 \mathrm{O} 2$ determines lenalidomide sensitivity. Blood. 2017:129(8):991-1007.

90. Gao S, Geng C, Song T, Lin X, Liu J, Cai Z, Cang Y. Activation of C-Abl Kinase Potentiates the Anti-myeloma Drug Lenalidomide by Promoting DDA1 Protein Recruitment to the CRL4 Ubiquitin Ligase. J Biol Chem. 2017;292(9): 3683-91.

91. Fang J, Liu X, Bolanos L, Barker B, Rigolino C, Cortelezzi A, Oliva EN, Cuzzola M, Grimes HL, Fontanillo C, et al. A calcium- and calpain-dependent pathway determines the response to lenalidomide in myelodysplastic syndromes. Nat Med. 2016;22(7):727-34.

92. Fischer ES, Bohm K, Lydeard JR, Yang H, Stadler MB, Cavadini S, Nagel J, Serluca F, Acker V, Lingaraju GM, et al. Structure of the DDB1-CRBN E3 ubiquitin ligase in complex with thalidomide. Nature. 2014;512(7512):49-53.

93. Chamberlain PP, Lopez-Girona A, Miller K, Carmel G, Pagarigan B, Chie-Leon B, Rychak E, Corral LG, Ren YJ, Wang M, et al. Structure of the human Cereblon-DDB1-lenalidomide complex reveals basis for responsiveness to thalidomide analogs. Nat Struct Mol Biol. 2014;21(9):803-9.

94. Petzold G, Fischer ES, Thoma NH. Structural basis of lenalidomide-induced CK1alpha degradation by the CRL4 ubiquitin ligase. Nature. 2016;532(7597): 127-30.

95. An J, Ponthier CM, Sack R, Seebacher J, Stadler MB, Donovan KA, Fischer ES. pSILAC mass spectrometry reveals ZFP91 as IMiD-dependent substrate of the CRL4(CRBN) ubiquitin ligase. Nat Commun. 2017;8:15398.

96. Sperling AS, Burgess M, Keshishian H, Gasser JA, Bhatt S, Jan M, Slabicki M, Sellar RS, Fink EC, Miller PG, et al. Patterns of substrate affinity, competition, and degradation kinetics underlie biological activity of thalidomide analogs. Blood. 2019:134(2):160-70.

97. Mali P, Yang L, Esvelt KM, Aach J, Guell M, DiCarlo JE, Norville JE, Church GM. RNA-guided human genome engineering via Cas9. Science. 2013; 339(6121):823-6.

98. Cong L, Ran FA, Cox D, Lin S, Barretto R, Habib N, Hsu PD, Wu X, Jiang W, Marraffini LA, et al. Multiplex genome engineering using CRISPR/Cas systems. Science. 2013;339(6121):819-23.

99. Jinek M, Chylinski K, Fonfara I, Hauer M, Doudna JA, Charpentier E. A programmable dual-RNA-guided DNA endonuclease in adaptive bacterial immunity. Science. 2012;337(6096):816-21.

100. Wang $H$, Yang $H$, Shivalila CS, Dawlaty MM, Cheng AW, Zhang F, Jaenisch $R$. One-step generation of mice carrying mutations in multiple genes by CRIS PR/Cas-mediated genome engineering. Cell. 2013:153(4):910-8.

101. Georgiadis C, Preece R, Nickolay L, Etuk A, Petrova A, Ladon D, Danyi A, Humphryes-Kirilov N, Ajetunmobi A, Kim D, et al. Long Terminal Repeat
CRISPR-CAR-Coupled "Universal" T Cells Mediate Potent Anti-leukemic Effects. Mol Ther. 2018;26(5):1215-27.

102. Ren J, Liu X, Fang C, Jiang S, June CH, Zhao Y. Multiplex Genome Editing to Generate Universal CAR T Cells Resistant to PD1 Inhibition. Clin Cancer Res. 2017;23(9):2255-66.

103. Zhao J, Lin Q, Song Y, Liu D. Universal CARs, universal T cells, and universal CAR T cells. J Hematol Oncol. 2018;11(1):132.

104. Zhao J, Song Y, Liu D. Clinical trials of dual-target CAR T cells, donor-derived CAR T cells, and universal CAR T cells for acute lymphoid leukemia. J Hematol Oncol. 2019;12(1):17.

105. Doudna JA. The promise and challenge of therapeutic genome editing. Nature. 2020;578(7794):229-36.

106. Matharu N, Ahituv N. Modulating gene regulation to treat genetic disorders Nat Rev Drug Discov. 2020;19(11):757-75.

107. Shalem O, Sanjana NE, Hartenian E, Shi X, Scott DA, Mikkelsen TS, Heckl D, Ebert BL, Root DE, Doench JG, et al. Genome-scale CRISPR-Cas9 knockout screening in human cells. Science. 2014:343(6166):84-7.

108. Chen S, Sanjana NE, Zheng K, Shalem O, Lee K, Shi X, Scott DA, Song J, Pan JQ, Weissleder R, et al. Genome-wide CRISPR screen in a mouse model of tumor growth and metastasis. Cell. 2015;160(6):1246-60.

109. Konermann S, Brigham MD, Trevino AE, Joung J, Abudayyeh OO, Barcena C Hsu PD, Habib N, Gootenberg JS, Nishimasu H, et al. Genome-scale transcriptional activation by an engineered CRISPR-Cas9 complex. Nature. 2015;517(7536):583-8.

110. Fellmann C, Gowen BG, Lin PC, Doudna JA, Corn JE. Cornerstones of CRISPRCas in drug discovery and therapy. Nat Rev Drug Discov. 2017;16(2):89-100.

111. Gopalakrishnan R, Matta H, Tolani B, Triche T Jr, Chaudhary PM. Immunomodulatory drugs target IKZF1-IRF4-MYC axis in primary effusion lymphoma in a cereblon-dependent manner and display synergistic cytotoxicity with BRD4 inhibitors. Oncogene. 2016;35(14):1797-810.

112. Patil A, Manzano M, Gottwein E. CK1alpha and IRF4 are essential and independent effectors of immunomodulatory drugs in primary effusion lymphoma. Blood. 2018;132(6):577-86.

113. Yamamoto J, Suwa T, Murase $Y$, Tateno $S$, Mizutome $H$, Asatsuma-Okumura T, Shimizu N, Kishi T, Momose S, Kizaki M, et al. ARID2 is a pomalidomidedependent CRL4CRBN substrate in multiple myeloma cells. Nat Chem Biol. 2020;16(11):1208-17.

114. Rasco DW, Papadopoulos KP, Pourdehnad M, Gandhi AK, Hagner PR, Li Y, Wei X, Chopra R, Hege K, DiMartino J, et al. A First-in-Human Study of Novel Cereblon Modulator Avadomide (CC-122) in Advanced Malignancies. Clin Cancer Res. 2019;25(1):90-8.

115. Nastoupil LJ, Bijou F, Ribrag V, Chavez JC, Witzig TE, Andorsky DJ, Klein LM, Greenwald D, Santoro A, Corradini P, et al. Avadomide (CC-122), a Novel Cereblon Modulating Agent, Plus Rituximab in Patients with Relapsed or Refractory Follicular Lymphoma. Blood. 2018;132(Supplement 1):1602.

116. Michot JM, Bouabdallah R, Doorduijn JK, Vitolo U, Kersten MJ, Chiappella A, Zinzani PL, Salles G, Bijou F, Sarmiento R, et al. Avadomide (CC-122), a Novel Cereblon Modulating Agent, in Combination with Obinutuzumab (GA101) in Patients with Relapsed or Refractory B-Cell Non-Hodgkin Lymphoma. Blood. 2018;132(Supplement 1):449.

117. Schafer PH, Ye Y, Wu L, Kosek J, Ringheim G, Yang Z, Liu L, Thomas M, Palmisano M, Chopra R. Cereblon modulator iberdomide induces degradation of the transcription factors Ikaros and Aiolos: immunomodulation in healthy volunteers and relevance to systemic lupus erythematosus. Ann Rheum Dis. 2018;77(10):1516-23.

118. Lonial S, Amatangelo M, Popat R, Minnema MC, Zonder JA, Larsen J, Oriol Rocafiguera A, Campagnaro EL, Rodriguez Otero P, Badros AZ, et al. Translational and Clinical Evidence of a Differentiated Profile for the Novel CELMoD, Iberdomide (CC-220). Blood. 2019;134(Supplement 1):3119.

119. Gaudy A, Atsriku C, Ye Y, MacGorman K, Liu L, Xue Y, Surapaneni S, Palmisano M. Evaluation of iberdomide and cytochrome p450 drug-drug interaction potential in vitro and in a phase 1 study in healthy subjects. Eur J Clin Pharmacol. 2021;77(2):223-31.

120. Ye Y, Gaudy A, Schafer P, Thomas M, Weiss D, Chen N, Liu L, Xue Y, Carayannopoulos L, Palmisano M. First-in-Human, Single- and MultipleAscending-Dose Studies in Healthy Subjects to Assess Pharmacokinetics, Pharmacodynamics, and Safety/Tolerability of Iberdomide, a Novel Cereblon E3 Ligase Modulator. Clin Pharmacol Drug Dev. 2020. https://doi.org/10.1 002/cpdd.869.

121. Pettersson M, Crews CM. PROteolysis TArgeting Chimeras (PROTACs) - Past, present and future. Drug Discov Today Technol. 2019;31(1):15-27. 
122. Li X, Song Y. Proteolysis-targeting chimera (PROTAC) for targeted protein degradation and cancer therapy. J Hematol Oncol. 2020;13(1):50.

123. He Y, Khan S, Huo Z, Lv D, Zhang X, Liu X, Yuan Y, Hromas R, Xu M, Zheng $G$, et al. Proteolysis targeting chimeras (PROTACs) are emerging therapeutics for hematologic malignancies. J Hematol Oncol. 2020;13(1):103.

124. Liu J, Ma J, Liu Y, Xia J, Li Y, Wang ZP, Wei W. PROTACs: A novel strategy for cancer therapy. Semin Cancer Biol. 2020;67(Pt 2):171-9.

125. Zorba A, Nguyen C, Xu Y, Starr J, Borzilleri K, Smith J, Zhu H, Farley KA, Ding W, Schiemer J, et al. Delineating the role of cooperativity in the design of potent PROTACs for BTK. Proc Natl Acad Sci U S A. 2018;115(31):E7285-E92.

126. Lai AC, Toure M, Hellerschmied D, Salami J, Jaime-Figueroa S, Ko E, Hines J, Crews CM. Modular PROTAC Design for the Degradation of Oncogenic BCRABL. Angew Chem Int Ed Engl. 2016;55(2):807-10.

127. Winter GE, Buckley DL, Paulk J, Roberts JM, Souza A, Dhe-Paganon S, Bradner JE. DRUG DEVELOPMENT. Phthalimide conjugation as a strategy for in vivo target protein degradation. Science. 2015;348(6241):1376-81.

\section{Publisher's Note}

Springer Nature remains neutral with regard to jurisdictional claims in published maps and institutional affiliations.

Ready to submit your research? Choose BMC and benefit from:

- fast, convenient online submission

- thorough peer review by experienced researchers in your field

- rapid publication on acceptance

- support for research data, including large and complex data types

- gold Open Access which fosters wider collaboration and increased citations

- maximum visibility for your research: over $100 \mathrm{M}$ website views per year

At $\mathrm{BMC}$, research is always in progress.

Learn more biomedcentral.com/submissions 